\title{
Comparing Usa and Mexico Response to Covid as well as Incidence and Death toll for the First 6 Months from February 2020 to august 2020 and the Pandemic on June 1st 2021
}

\author{
Gabriel Miranda Nava ${ }^{1 *}$, Maria Preciado ${ }^{2}$, Luis Gallo ${ }^{2}$ \\ ${ }^{1}$ Military Medical Specialist in neurology, neurophysiology and sleep diseases, Mexico \\ ${ }^{2}$ Lamar Guadalajara University. MD.
}

* Corresponding Author: Gabriel Miranda Nava, Military Medical Specialist in neurology, neurophysiology and sleep diseases, Mexico.. Received date: June 15, 2021; Accepted date: August 02, 2021; Published date: August 07,2021

Citation: Gabriel Miranda Nava, Maria Preciado, Luis Gallo. (2021) Comparing Usa and Mexico Response to Covid as well as Incidence and Death toll for the First 6 Months from February 2020 to august 2020 and the Pandemic on June 1st 2021. J. Neuroscience and Neurological Surgery. 9(3); DOI:10.31579/2578-8868/197

Copyright: (c) 2021 Juan Carlos Gómez-Vega, This is an open-access article distributed under the terms of The Creative Commons Attribution License, which permits unrestricted use, distribution, and reproduction in any medium, provided the original author and source are credited

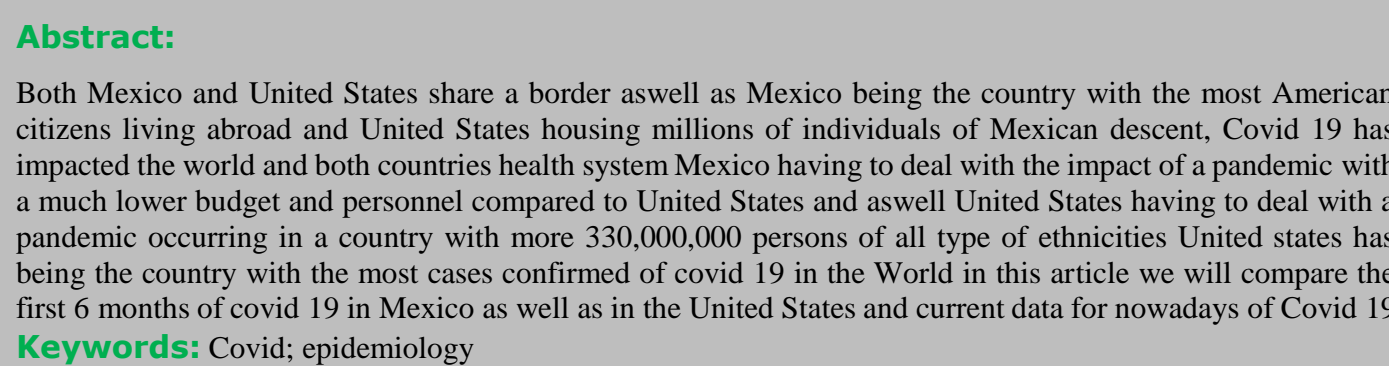

\section{Introduction}

When we compare how the pandemic happened in both contries we can see that there was a time from difference in between Mexico having its first Covid 19 case compare to Unites States, In United States the first recorded case happened on January while the first covid 19 case in Mexico occurred in February.

In 2019 the novel coronavirus was first detected in Wuhan, China, promptly new cases were confirmed all over the world. On January 19 of 2020 a 35-year-old man with travel history and 4 days of cough and suggestive fever walked into a clinic in Snohomish Country, Washington; by January 20 the first case of COVID 19 in USA was reported. Six days later on January 26 of 2020 Washington announced the first two deaths in the country caused by the pandemic. Washington had the highest absolute number of confirmed cases and the highest number per capita of any state in the country, until it was surpassed by New York State on April 10, 2020. [1]

For Mexico we know that the first confirmed case occurred in a 35 year old male it was detected in Mexico City which for this case was the city with the highest number of cases in general most of them confirmed with PCR. This 35 year old male had traveled to Italy days before being confirmed with Covid 19, this was confirmed on the same night by the Director General of Epidemiology and National Focal Point for International Health Regulations

In Mexico most cases of covid occurred in Mexico City [1] 


\section{Mexico City}

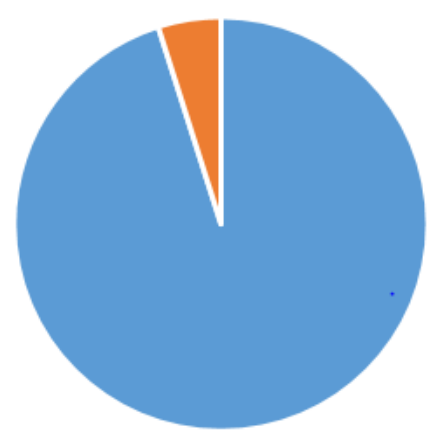

- Number of cases $\quad$ Number of deaths

Figure 1 Actual Mexico City statistics. (1) Figure 1

In Mexico city most cases of covid have occurred over here 664,000 cases occurred out of which 34,292 patients died.

The average age in Mexico city for most cases was in the age between 46 years old, until April, 12,000 cases had being confirmed ranging between 30-59 years old, and most cases were male patients, at least $58 \%$ of the patients hospitalized for covid in Mexico city after the first 3 months were male patients. By may 2020 more than 87,512 cases had being confirmed in Mexico out of them 9779 cases were fatal. Mean while by June 2020 220,000 cases of covid had being confirmed out of this 23,389 were active as well as 27,121 of them were fatal, with 556,000 thousand individuals being negative for covid 19 .

By July and august 2020 395,000 cases of covid had being confirmed most patients being male patients most of them with comorbidities, and 44,000 deaths confirmed. 256,000 recovered cases of covid 19. By August 2020 537,000 cases of covid had being confirmed in Mexico
In the first 6 months of covid $19 \quad 537,000$ cases of covid had being confirmed in Mexico with a death toll of 44,000 deaths confirmed in Mexico out of this most cases occurred in Mexico City

When we compared this numbers we can see that in United States the first confirmed case occurred on March $1^{\text {st }}$ 2020. On Sunday March 1 of 2020 the first case OF COVID 19 was confirmed and reported in New York; by April 10 of 2020 New York was reported with more confirmed cases than any other country outside the USA. After 3 months into the pandemic 203,000 cases of laboratory confirmed cases were reported in NYC, positioning New York as the epicenter of the disease in United states. [3] The crude fatality rate among confirmed cases was $9.2 \%$ overall and $32.1 \%$ among hospitalized patients. Incidence, hospitalization rates, and mortality were highest among Black/African American and Hispanic/Latino persons, as well as those who were living in neighborhoods with high poverty, aged $\geq 75$ years, and with underlying medical conditions. [4]

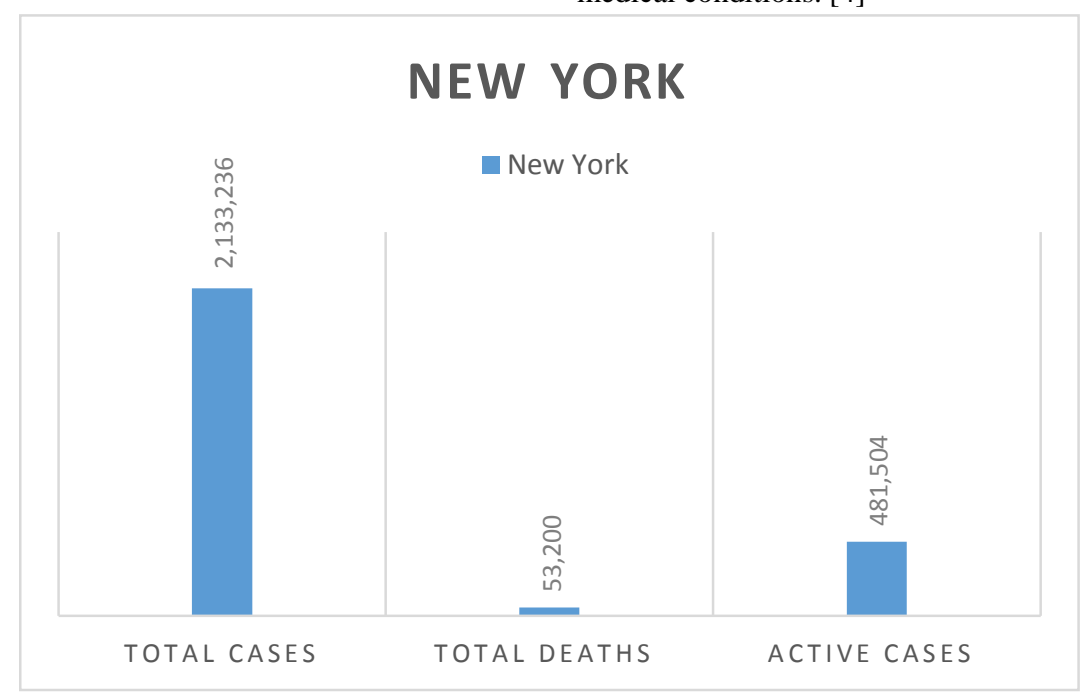

Figure 2: Actual New York statistics. ${ }^{(2)}$ 
When we compared the numbers seen in the two cities with the most cases we can see that New York City had amazed more than 203,000 cases which if it were compared to Mexico City we can see that from the first case confirmed in January to April 12,000 cases had being confirmed for covid 19 , out of this number this represents roughly $5.9 \%$ of the number of cases reported in New York most cases being male patients over 60 years of age and with comorbidities. On January 31 the center for disease control and prevention confirmed the first case in San Jose, California. [5] By mid-October California, Texas and Florida exceeded NYC death rate and California became the state with the higher rates of damage by the COVID 19. [6]

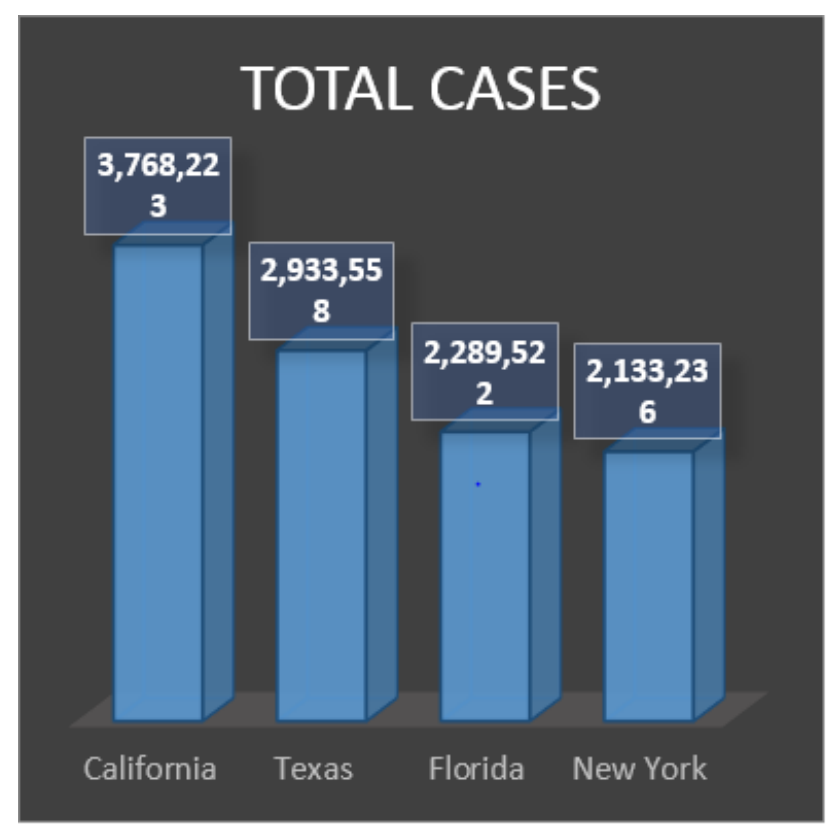

Figure 3 Comparison of actual total cases ${ }^{(2)}$

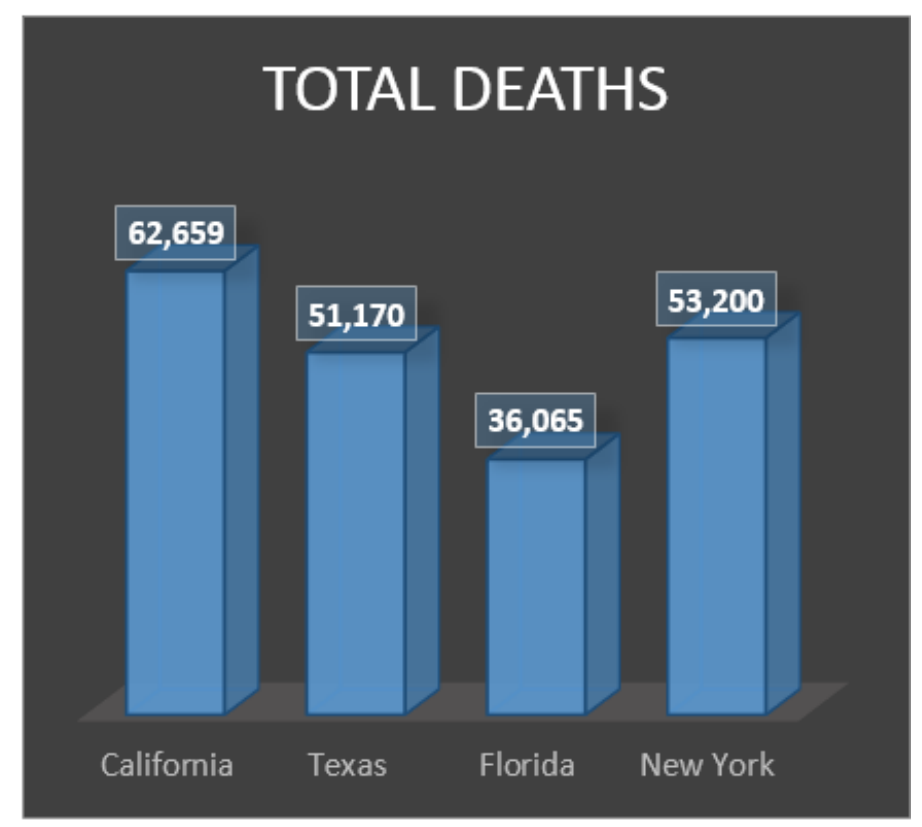

Figure 4 Comparison of actual total deaths (2)

Today's data situate Vermont as the state with less total cases and death rate reported and Louisiana, Hawaii, Nebraska and Maine have no active cases. [2]

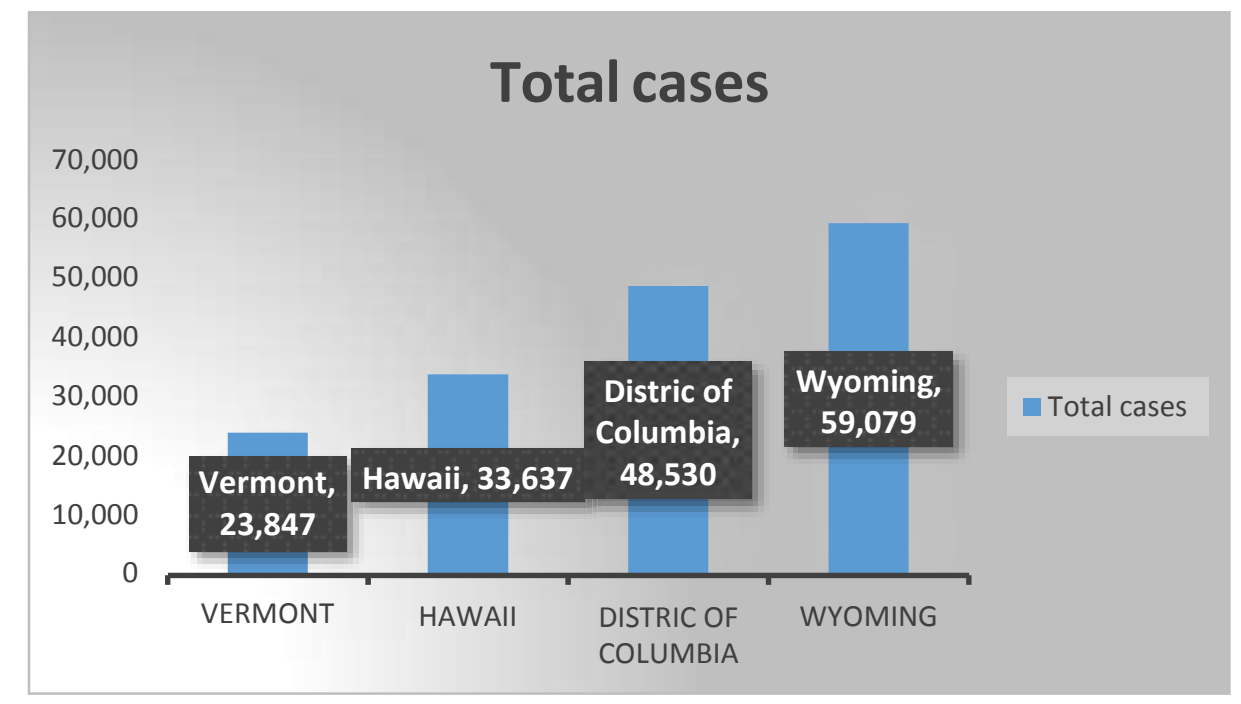

Figure 5 actual total cases statistics ${ }^{(2)}$

Today United States has the first place in ranking of COVID worldwide with a total case of 33,695,916 cases reported through all the country. [2] 


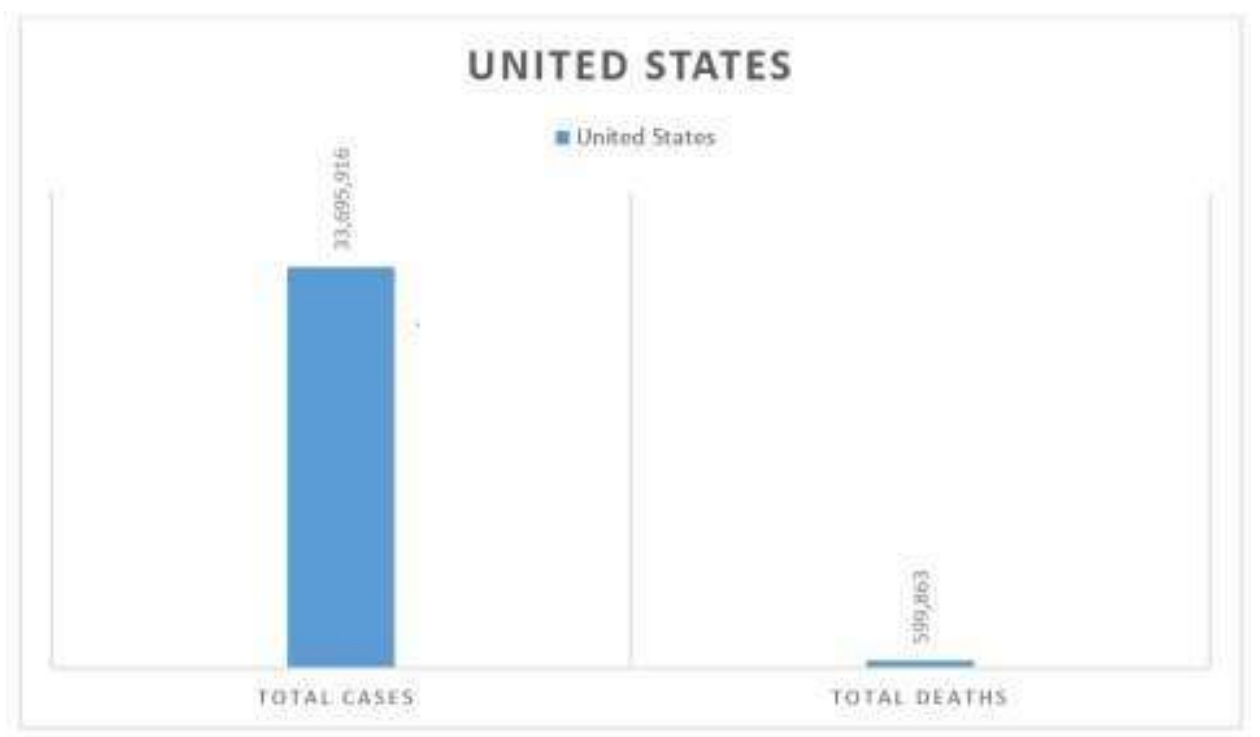

Figure 6 Actual country statistics (2)

on June $01^{\text {st }} 20212,605,303$ patients have being confirmed with covid 19 out of them there has being a death toll of 227,840 cases and 1,930,608 cases have recovered most cases have occurred in Mexico City and there has being a significant decline in the number of cases of covid 19 in the country because vaccinations have being applied to geriatric individuals aswell as in the United States most individuals have being vaccinated In the United States $28,756,489$ cases have being confirmed with 515,000 patients dying due to covid 19 , data being from march $07^{\text {th }} 2021$. With 8134 patients being hospitalized in the ICU and 2802 patients under mechanical ventilator.

We can see the the countries had there most cases in the biggest cities that they have both New York as well as Mexico City were the epicenter for the disease in both countries, with most cases having being confirmed in the areas with the most poverty and being spread between people of older age raging from 60 years old or more years, Mexico has had a number of $2,605,303$ cases out of a population of $130,000,000$ people having a that is $2 \%$ of their population meanwhile the United States had a number of cases of $8.7 \%$ of their populations has being confirmed to had contracted covid 19 during the pandemic, both countries have struggle with the pandemic but United States has applied far more test meanwhile Mexico has one of the lowest percentages of patients tested for covid 19, most patients don't arrive at the Hospital until it is too late because they don't trust the government nor the health system in Mexico aswell as Mexico City, for the Mexico numbers we know that most patients don't believe covid 19 exist and believe the pandemic to be a haux of some sort.

Vaccinations are being applied in both countries with US health system recovering financially from the pandemic, the Mexican health system has being overwhelmed too by the covid 19 pandemic.

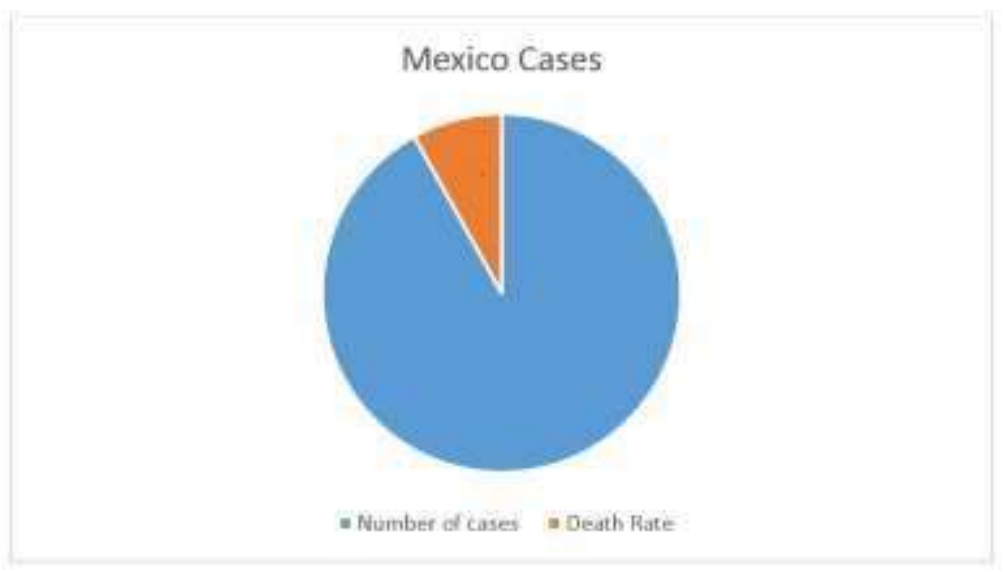

Figure 7 Actual Country statistics

\section{Reference}

1- Hannah Ritchie. Coronavirus Pandemic, January 01 2021 h

2- Rebeca Flores. Primer caso confirmado de covid 19. mx/trending/coronavirus/2020/05/30/5ed1dd55268e3ec4168b 45ac.html

3- V. Suarez, M Suarez Quesada. Epidemiologia de covid 19 en Mexico February 19-April 2020 
4- Michelle L. First case of Novel Coronavirus in the United States, The New England Journal of Medicine January 31, 2020

5- World Meter coronavirus report, last update May 16 of 2021

6- Corinne N. Thompson. Covid 19 outbreak- New York, CDC centers for disease and control prevention Nov 20, 2020

7- Natasha Priya Dyal. First Case of COVID-19 in NYC, First Death Reported in Washington State. March 3, 2020
Nancy Ortiz. Epidemiologic findings from case investigations and contact tracing for first 200 cases of coronavirus disease, Santa Clara Country, California, USA. CDC Centers for Disease Control and Prevention. May 52021

9- Jianyong Wu. Pattern recognition of the COVID-19 Pandemic in the United States: Implications for Disease Migration. International Journal of Environmental Research and Public Health. March 3 of 2021 $8-$

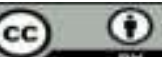

This work is licensed under Creative

Commons Attribution 4.0 License

\section{To Submit Your Article Click Here: Submit Manuscript}

DOI:10.31579/2578-8868/197
Ready to submit your research? Choose Auctores and benefit from:

* fast, convenient online submission

* rigorous peer review by experienced research in your field

* rapid publication on acceptance

* authors retain copyrights

* unique DOI for all articles

* immediate, unrestricted online access

At Auctores, research is always in progress.

Learn more https://www.auctoresonline.org/journals/neuroscience-and$\underline{\text { neurological-surgery }}$ 